and use it to hold the lid up while drinking. Many rats also show a preference for the drinking fountain that is in an uncrowded location.

Possibly our colleagues interested in animal psychology and behaviour might suggest that these observations raise the question of right- or left-pawed preference in rats. Perhaps many of the animals profer to drink in comfort. The fact remains that neither dietary deficiency nor 'genotype' was concerned in most of the cases of 'alcoholism' observed in the twenty-five rats given a choice of dilute alcohol or tap-water to drink, since the 'disease' was 'cured' by changing the positions of the fountains.

This communication is to provide a warning that the size and shape of cage and the arrangement of self-selection dispensers may exert a strong influence on the apparent 'preference' of rats. Details of the work will be published shortly.

R. J. G. Gillespie

\section{C. Lucas}

Banting and Best Department of Medical Research,

University of Toronto.

Toronto.

July 26.

${ }^{1}$ Best, C. H., Hartroft, W. S., Lucas, C. C., and Ridout, J. H., Brit. Med. J., ii, 1001 (1949).

${ }^{2}$ Mardones, J., and Onfray, H., Rev. Chil. Mig. Med. Prev., 4, 293 $(1942) ; 5,17(1942)$

${ }^{3}$ Mardones, J., Segovia, N., and Onfray, E., Arch. Biochem., 9, 401 $(1946)$.

4 Mardones, J., Segovia, N., and Hederra, A., Quart. J. Stud. Alc., 14, 1 (1953).

'Williams, R. J., Quart. J. Stud. Alc., 7, 567 (1947); J. Clin. Nutr., 1, $32(1952)$

- Williams, R. J., Berry, T. J., and Beerstecker, jun., E., Arch. Biochem., 23, 275 (1949).

\section{The Quadratic Relation in Differential Growth}

IT was shown ${ }^{1}$ that the growth in width of the abdomen of the female pea crab, Pinnotheres pisum, did not show simple allometry ${ }^{2}$, but a continuously variable allometric relation, relative to carapace width. For purely empirical purposes a general polynomial relation was fitted to the two measurements ${ }^{3}$, but the quadratic proved a very good 'fit' and it was later pointed out (Reeve, E. C. R., personal communication) that no appreciable improvement was effected by fitting higher powers of the polynomial. It is possible, therefore, that the relation between abdomen-width $(y)$ and carapace-width $(x)$ may be defined, not only adequately but also significantly, by the simple equation $y=a+b x+c x^{2}$, where $a, b, c$ are constants for any particular abdominal segment, and are parameters for the abdomen as a whole ${ }^{8}$.

It seems worth considering possible implications of this relation, should it prove to have more than empirical significance. The second differential of $y$ with respect to $x$ is a constant : $\mathrm{d}^{2} y / \mathrm{d} x^{2}=2 c$, which implies a constant differential acceleration of growth between the two measurements. At first glance this might seem to have little biological meaning, but supposing that the rate of protein synthesis, and therefore of growth, should be related to the amount of a critical growth-promotor or catalyst present in the cell, for example, possibly pentose nucleic acid then the acceleration of growth should bo related to the rate (velocity) of synthesis of this promotor, and therefore a constant differential acceleration of the two measurements could be due to a constant differential pattern of synthesis of pentose nucleic acid in the body. This would apply equally if the two accelerations are negative, as in fact they usually are, in Metazoa; here a constant differential pattern of depletion of pentose nucleic acid, by dilution, exhaustion, ete., is visualized.

Polynomial relations have already been advocated from time to time. A logical merit of such a relation in differential growth is that it could be valid both for $y$ and for the constituent parts of $y$, unlike the simple allometry relation and many others. Also, the second differential implies that reciprocally it would be equally valid to express $x$ as a quadratic in $y$. It has been shown further ${ }^{3,5}$ that a simple, quadratic is technically useful, permitting various integrative algebraical exercises, aimed at defining shape and form as continuous functions of space and time. Other potentialities of the relation need not. be considered here. Other examples of continuously variable allometry have been recorded and both these and other examples of differential growth might usefully be tested for a quadratic relation. Where two compared measurements are of different orders of dimension, a more complex relation would be expected and it is important to reduce them to the same dimensional order before testing for the quadratic (or any other) relation.

The limitations and dangers of the mathematical approach to growth are appreciated, but on the other hand no possibly fruitful relation can be neglected. Mathematical approaches have never failed to stimulate interest and further work.

A. E. NEedhaM

Dept. of Zoology and Comparative Anatomy,

University Museum, Oxford.

Aug. 7.

1 Williams, G., and Needham, A. E., Proc. Zool. Soc., A, 108, 539 (1938).

${ }^{2}$ Huxley, J. S., Needham, J., and Lerner, I. M., Nature, 148, 225 (1941).

${ }^{3}$ Needham, A. E., Proc. Roy. Soc., B, 137, 115 (1950),

- Fowden, L., New Biol., 23, 65 (1957).

"Medawar, P. B., Proc. Roy. Soc., B, 132, 133 (1944).

\section{Production of Sclerotic Granules by Streptomyces sp.}

ThIRUMalachar ${ }^{i}$ has proposed a new genus Chainia of the order Actinomycetales in honour of Prof. E. B. Chain, of the Istituto Superiore Sanità, Rome. The chief distinguishing character of the genus is the formation of sclerotic granules, $16-75 \mu$ in diameter, on glucose peptone medium. C. antibiotica, the only species described by him, has a branching non-septate mycelium without true aerial mycelium and spores.

Solerotic granules were observed in a strain of Streptomyces griseus isolated from soil at Lethbridge, Alberta, Canada, during my investigations on an anti-fungal antibiotic produced by this organism. These granules developed abundantly on trypticase soy agar (Baltimore Biological Laboratory, Baltimore, Maryland) when the organism was streaked on the plates and incubated at $25^{\circ}$ and $37^{\circ} \mathrm{C}$. for $36^{\circ} \mathrm{hr}$. On this medium no aerial mycelium and spores aro produced. In granule formation a hypha thickens and other hyphæ start surrounding it, resulting in the development of a brownish-green mass of sclerotic tissue which eventually becomes black. In the early 